\title{
Claudin expression in follicle-associated epithelium of rat Peyer's patches defines a major restriction of the...
}

Article in Acta Physiologica · January 2016

DOI: $10.1111 /$ apha.12559 · Source: PubMed

CITATION

1

5 authors, including:

\section{Alexander Georgievich Markov}

Saint Petersburg State University

45 PUBLICATIONS 245 CITATIONS

SEE PROFILE

\section{Judith Radloff}

Freie Universität Berlin

4 PUBLICATIONS 3 CITATIONS

SEE PROFILE
READS

36

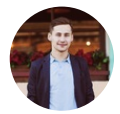

Falchuk Evgeny

Saint Petersburg State University

5 PUBLICATIONS 11 CITATIONS

SEE PROFILE

Salah Amasheh

Freie Universität Berlin

92 PUBLICATIONS 3,745 CITATIONS

SEE PROFILE

Some of the authors of this publication are also working on these related projects: 


\begin{tabular}{|l|c|c|c|l|l|}
\hline \multirow{2}{*}{2} & A P H A & 12559 & \multirow{2}{*}{ WILEY } & Dispatch: 10.8 .15 & CE: Geetha \\
\cline { 2 - 3 } & Journal Code & Manuscript No. & & No. of pages: 8 & PE: Sumathi \\
\hline
\end{tabular}

\section{Claudin expression in follicle-associated epithelium of rat Peyer's patches defines a major restriction of the paracellular pathway}

D A. G. Markov, ',* E. L. Falchuk,, '* N. M. Kruglova,' J. Radloff ${ }^{2}$ and S. Amasheh ${ }^{2}$

I Institute of General Physiology, Biological Faculty, St. Petersburg State University, St. Petersburg, Russia

2 Institute of Veterinary Physiology, Freie Universität Berlin, Berlin, Germany

Received I5 April 2015,

revision requested 19 May 2015 , revision received 22 June 2015 , accepted 24 July 2015

Correspondence: S. Amasheh, Institute of Veterinary Physiology, Oertzenweg 19b, 14163 Berlin, Germany.

E-mail: salah.amasheh@fu-berlin.de

*These authors contributed equally to this work.

\begin{abstract}
Aim: Members of the tight junction protein family of claudins have been demonstrated to specifically determine paracellular permeability of the intestinal epithelium. In small intestinal mucosa, which is generally considered to be a leaky epithelium, Peyer's patches are a primary part of the immune system. The aim of this study was to analyse the tight junctional barrier of follicle-associated epithelium covering Peyer's patches (lymphoid follicles).

Methods: Employing small intestinal tissue specimens of male Wistar rats, electrophysiological analyses including the Ussing chamber technique, marker flux measurements and one-path impedance spectroscopy were performed. Morphometry of HE-stained tissue sections was taken into account. Claudin expression and localization was analysed by immunoblotting and confocal laser scanning immunofluorescence microscopy.

Results: Almost twofold higher parameters of epithelial and transepithelial tissue resistance and a markedly lower permeability for the paracellular permeability markers 4 and $20 \mathrm{kDa}$ FITC-dextran were detected in follicle-associated epithelium compared to neighbouring villous epithelium. Analysis of claudin expression and localization revealed a stronger expression of major sealing proteins in follicle-associated epithelium, including claudin-1, claudin-4, claudin-5 and claudin-8. Therefore, the specific expression and localization of claudins is in accordance with barrier properties of follicle-associated epithelium vs. neighbouring villous epithelium.

Conclusion: We demonstrate that follicle-associated epithelium is specialized to ensure maximum restriction of the epithelial paracellular pathway in Peyer's patches by selective sealing of tight junctions. This results in an exclusive transcellular pathway of epithelial cells as the limiting and mandatory route for a controlled presentation of antigens to the underlying lymphocytes under physiological conditions.

Keywords impedance spectroscopy, tight junctions, tissue barrier, villous epithelium.
\end{abstract}

Tight junctions (TJ)s have been demonstrated to provide the primary limiting structure determining epithelial barrier function in a wide variety of tissues and organs, such as kidney, intestine, lungs and mammary glands (Amasheh et al. 2011, Markov et al. 2012, 2 Koval 2013).
In recent years, it has been demonstrated that a number of members belonging to the tetraspan $\mathrm{TJ}$ protein family of claudins specifically determine tissueand organ-specific barrier properties (Markov et al. 2010, Amasheh et al. 2011). Among this family, three groups have been differentiated, namely (i) sealing 
claudins, (ii) claudins mediating paracellular permeability and (iii) claudins with ambiguous function (Amasheh et al. 2011). On molecular level, the combination of claudin within TJ strands has been reported, which indicates specific interactions within defined clusters (Van Itallie \& Anderson 2014, Markov et al. 2015).

Along the longitudinal axis of the small intestine, the expression of TJ proteins shows a very distinct pattern, which is in accordance with general parameters of barrier function (Markov et al. 2010). Whereas general expression and localization of $\mathrm{TJ}$ proteins in small intestinal villous epithelium has been shown, information about specific expression in follicle-associated epithelium (FAE) is scarce. The jejunum expression of tightening TJ proteins including claudin-1, claudin- 3 and claudin-5 as well as the expression of claudin-2 has been reported, which mediates paracellular permeability for $\mathrm{Na}^{+}$and water (Amasheh et al. 2002, Rosenthal et al. 2010).

Information regarding claudin expression in FAE is limited to the report that claudin-2, claudin-3, claudin- 4 and occludin in murine FAE can be detected by means of immunohistochemistry (Clark \& Hirst 2002, Tamagawa et al. 2003). However, a quantitative comparison of TJ protein expression in FAE and neighbouring villous epithelium in context with functional barrier parameters has not been shown, yet.

Mucosa of the small intestine is a contact region of the body exposed to a vast variety of exogenous molecules including toxins and undigested food particles. Peyer's patches (PP) are an important part of the gut-associated lymphoid tissue (GALT) that plays a significant role in host defence from pathogens and primarily localizes in the distal small intestine (Jung et al. 2010).

Structurally, PP consist of lymphoid follicles covered by the FAE, which functions as a tissue barrier between intestinal content and immune cells (Keita \&

3 Söderholm 2012). Within PP epithelium, M cells are responsible for the translocation and presentation of bacterial and viral epitopes to the immune cells via transcytosis, and this presentation induces activation of B- and T lymphocytes in the follicular area of PP (Gebert et al. 1996). Whereas this transcellular translocation has been described in more detail, limited information is available regarding the characteristics of the paracellular pathway and its contribution to immunological function of PP.

Comparison of transepithelial resistance of rabbit PP and villous epithelium revealed a general difference, with markedly higher values in FAE compared to neighbouring villous epithelium (Brayden \& Baird 1994). However, considering that the transepithelial resistance is an integral index comprising the resistance of all tissue layers during electrophysiological experiments, the contribution of FAE barrier function could not be determined exactly in previous studies. Therefore, the aim of our study was to differentially analyse the barrier function of PP epithelium and to correlate the functional insights gained with the expression and localization of the main determinants of intestinal TJs, the family of claudins.

\section{Material and methods}

Intestinal tissue specimens of untreated male Wistar rats were employed as reported previously (Markov et al. 2010, 2014). This study is conform with Persson (2013). Directly neighbouring adjacent jejunal tissue specimens of both PP and villous epithelium were visually selected employing a stereo microscope (Carl Zeiss, Jena, Germany) and were then used for electrophysiology, permeability assays, Western blot analysis and immunohistochemistry. Moreover, morphometric analysis of tissues was performed, taking into account the different architecture of the mucosa for correlation of the data.

\section{Morphometry}

The area of PP and villous samples from jejunum for electrophysiology and immunoblotting was limited by the Ussing chambers' aperture. Nonetheless, real or surface area (mucosal surface) of samples was higher compared to villous epithelium as a consequence of histological structure. To prevent the overestimation or underestimation of epithelial resistance, we performed a correction for surface area. For acquisition of a correction factor, we employed a common procedure used in other studies (Smith et al. 1980, Troeger et al. 2007).

Measurement of mean sizes of PP revealed a value of $12.5 \mathrm{~mm}^{2}$, containing 10 lymphoid follicles covering $8.9 \mathrm{~mm}^{2}$ of this area, while villous epithelia inside Peyer's patches preparations covered $3.6 \mathrm{~mm}^{2}$. Given a villus base area of $0.035 \mathrm{~mm}^{2}$, we can suppose that the tissue with a size $3.6 \mathrm{~mm}^{2}$ contains 103 villi in accordance with previous findings (Troeger et al. 2007).

Taking into account previous measurements of Smith et al. (1980), a follicle-associated epithelium surface area of $0.417 \mathrm{~mm}^{2}$ and a villi surface area of $0.127 \mathrm{~mm}^{2}$, whole PP surface area equals $17.2 \mathrm{~mm}^{2}$ $(10 \times 0.417+103 \times 0.127)$. The villous epithelium with the same size of serosal area $\left(12.5 \mathrm{~mm}^{2}\right)$ contains about 357 villi and has a surface area of $45.3 \mathrm{~mm}^{2}$. Therefore, the surface area ratio between villous tissue and PP epithelium used for the experiments is 2.62 . 


\section{Electrophysiology}

Ussing chamber technique was used to measure transepithelial resistance (TER) during $1 \mathrm{~h}$ of incubation as reported previously (Markov et al. 2010). Briefly, tissues were mounted in containers of Ussing chambers (exposed area: $0.13 \mathrm{~cm}^{2}$ ), and the bathing solution contained (in $\mathrm{mm}$ ) $\mathrm{Na}^{+}(140.5), \mathrm{K}^{+}$(5.4), $\mathrm{Ca}^{2+}$ (1.2), $\mathrm{Mg}^{2+}$ (1.2), $\mathrm{Cl}^{-}$(123.8), $\mathrm{HCO}_{3}^{-}$(21), $\mathrm{HPO}_{4}^{2-}(2.4), \mathrm{H}_{2} \mathrm{PO}_{4}^{-}(0.6), \mathrm{D}(+)$-glucose $(10), \mathrm{D}(+)$ mannose (10), b-OH-butyrate (0.5) and glutamine (2.5). During all experiments, the solution was gassed with $95 \% \mathrm{O}_{2}$ and $5 \% \mathrm{CO}_{2}$ at $37{ }^{\circ} \mathrm{C}$. In a separate set of experiments, one-path impedance spectroscopy was employed to analyse the contribution of epithelial $\left(\mathrm{R}^{\mathrm{epi}}\right)$ and subepithelial $\left(\mathrm{R}^{\mathrm{sub}}\right)$ resistance to TER as described previously in detail (model 1250 frequency response analyser and model 1286 electrochemical interface; Solartron Schlumberger, Farnborough, Hampshire, UK) (Markov et al. 2010); briefly, one-path impedance spectroscopy discriminates between $\mathrm{R}^{\text {epi }}$ and $\mathrm{R}^{\text {sub }}$, based on the model that the conductivity of the epithelial cell layer is dependent on frequency, in contrast to the subepithelial tissue layers which lack tight junctions (Amasheh et al. 2009a).

In an additional set of experiments, permeability assays for FITC-dextran molecules were performed in Ussing chambers as outlined above. After stabilization of electrophysiological parameters, $500 \mu \mathrm{l}$ of mucosal solution was replaced with an appropriate buffer, containing $4 \mathrm{kDa}$ or $20 \mathrm{kDa}$ FITC-dextran

4 (Sigma Aldrich, Germany) (final concentration $2 \mathrm{mg} \mathrm{ml}^{-1}$, respectively). Dextran fluxes were calculated from the amount of FITC-dextran in the basolateral compartment and measured with a fluorometer at $520 \mathrm{~nm}$ as reported in detail recently

5 (Dittmann et al. 2014); briefly, the apparent permeability $\mathrm{P}_{\text {app }}$ was calculated as $\mathrm{P}_{\text {app }}=(\mathrm{dQ} / \mathrm{dt}) /$ $(\mathrm{A} \times \mathrm{Co})$, with $\mathrm{dQ} / \mathrm{dt}$ describing the steady-state appearance rate of dextran in the acceptor chamber, the area $\mathrm{A}$ of exposed epithelium and the concentration Co of FITC-dextran in the donor chamber. Data were corrected employing a correction factor derived from morphometric analysis.

\section{Western blot and densitometry}

Western blot was performed as described previously (Markov et al. 2014). Briefly, tissues were homogenized in Tris-buffer containing (in $\mathrm{mm}$ ) Tris (20), $\mathrm{MgCl}_{2}$ (5), EDTA (1), EGTA (0.3) and protease inhibitors (Complete, Boehringer, Mannheim, Germany), and protein contents were determined using BCA protein assay reagent (Pierce, Rockford, IL, USA) and quantified with a plate reader (Tecan, Groedig, Austria). Samples were mixed with SDS buffer (Laemmli), loaded on a $12.5 \%$ SDS polyacrylamide gel and electrophoresed. Proteins were detected by immunoblotting, employing primary antibodies raised against occludin or claudin-1, claudin-2, claudin-3, claudin-4, claudin-5, claudin-7 and claudin-8 (Life Technologies, USA). Peroxidase-conjugated goat anti- 6 rabbit IgG or goat anti-mouse IgG antibodies and the chemiluminescence detection system Lumi-LightPLUS Western blotting kit (Roche, Mannheim, Germany) were used to detect bound antibodies. Signals were visualized by luminescence imaging (LAS-1000; Fujifilm, Tokyo, Japan), and densitometry was performed using AIDA and Biorad Quantity One software, taking into account beta-actin bands of self-same immunoblots, respectively. Data were corrected, employing a correction factor in accordance with morphometric analysis.

\section{Immunohistochemistry}

Immunohistochemistry of tissues was performed as described previously (Markov et al. 2014). Briefly, PP tissues were fixed in $4 \%$ formalin for $3 \mathrm{~h}$ at RT and, after dehydration, were embedded in paraffin. For immunostaining, paraffin was removed from crosssection $(4 \mu \mathrm{m})$ by xylol-ethanol gradient, and antibodies raised against claudin-1, claudin-2, claudin-3, claudin-4, claudin-5, claudin-7 and claudin-8 and occludin were used (Life Technologies). Slides were incubated with primary antibody and subsequently incubated with Alexa Fluor goat anti-rabbit and antimouse IgGs (Life Technologies) according to the manufacturer's instructions. Nuclei were stained with 4',6-diamidino-2-phenylindole (DAPI; $1: 5000$ ) prior to mounting of the sections in ProTags MountFluor (Biocyc, Luckenwalde, Germany). Specificity of signals was monitored by control stainings in which primary antibodies were omitted, as also performed with identical antibodies in our previous studies focusing on rat tissues (Markov et al. 2010, 2014, Hackel et al. 2012, Rittner et al. 2012). Confocal laser scanning microscopy was performed, employing microscopes of the Zeiss LSM510 and Leica TCS SP2 series (Zeiss, Jena; Leica Microsystems, Heidelberg, Germany).

\section{Statistical analysis}

Data are expressed as means \pm SEM. Statistical analysis was performed using Student's $t$ test. $P<0.05$ was considered significant. 


\section{Results}

\section{Histology}

Tissue preparation revealed the majority of PP in rat jejunum. For all experiments, areas of follicles of PP and area of adjacent neighbouring villous tissues were selected. HE staining revealed different mucosal surface areas according to the architecture of PP and adjacent neighbouring villous epithelia (Fig. 1). Tissues were morphometrically analysed for comparative approaches, taking into account the different mucosal surface area ratio between villous tissue and PP epithelium, resulting in a correction factor of 2.62 .

\section{Electrophysiology}

Conventional Ussing chamber technique was used to investigate values and stability of TER of adjacent parts of small intestinal tissue with and without PP for $1 \mathrm{~h}$. Whereas villous control epithelium showed an TER of $60.9 \pm 4.4 \Omega \mathrm{cm}^{-2}$, TER of PP epithelium was higher $\left(89 \pm 6.4 \Omega \mathrm{cm}^{-2}\right)$ and was further elevated after surface correction of the data $\left(227.9 \pm 16.4 \Omega \mathrm{cm}^{-2}\right)$ (Fig. 2). All values remained stable over the time course of electrophysiological experiments.

One-path impedance spectroscopy was employed to discriminate between the contribution of $\mathrm{R}^{\mathrm{epi}}$ and $\mathrm{R}^{\mathrm{sub}}$ to TER (Fig. 3). Whereas $\mathrm{R}^{\text {epi }}$ of controls was $12.6 \pm 1.3 \Omega \mathrm{cm}^{-2}, \mathrm{R}^{\text {epi }}$ of PP was markedly higher $\left(30.2 \pm 5.4 \Omega \mathrm{cm}^{-2}\right.$, Fig. 3a) and further elevated after correction according to mucosal surface (79.1 $\pm 14.5 \Omega \mathrm{cm}^{-2}$, not shown). $\mathrm{R}^{\text {sub }}$ revealed values of $37.8 \pm 1.6$ and $66.1 \pm 5.7 \Omega \mathrm{cm}^{-2}$, reflecting different submucosal thickness of tissue specimens (Fig. $3 b ; n=19$ and 25 , respectively, $* * * P<0.001$ ).

Measurement of paracellular permeability was performed using $4 \mathrm{kDa}$ and $20 \mathrm{kDa}$ FITC-dextran

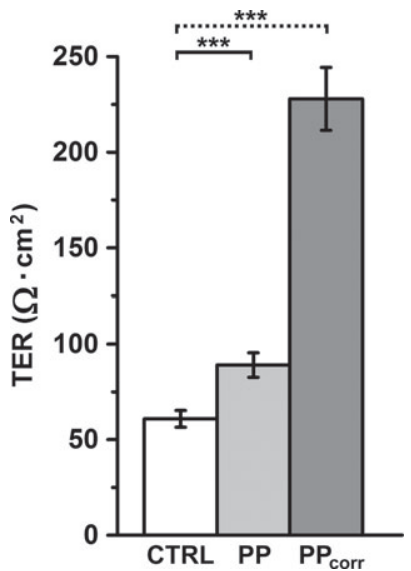

Figure 2 TER results of Ussing chamber experiments. Measurement of transepithelial resistance (TER) of jejunal villous epithelium and Peyer's patches (PP) revealed markedly higher values for PP epithelium, which were further elevated after correction by morphometry $\left(\mathrm{PP}_{\text {corr }}\right), n=22$, respectively, $* * * P<0.001$.

(Fig. 4). Permeability for both $4 \mathrm{kDa}$ and $20 \mathrm{kDa}$ FITC-dextran was markedly lower in PP compared to neighbouring adjacent villous epithelium (Fig. 4a: $0.047 \pm 0.015 \times 10^{-6} \mathrm{~cm} \mathrm{~s}^{-1}$ vs. $0.324 \pm 0.066 \times$ $10^{-6} \mathrm{~cm} \mathrm{~s}^{-1}$; Fig. 4b: $0.039 \pm 0.004 \times 10^{-6} \mathrm{~cm} \mathrm{~s}^{-1}$ vs. $\left.0.104 \pm 0.005 \times 10^{-6} \mathrm{~cm} \mathrm{~s}^{-1}\right)(n=3, * P<0.05$, $* * * P<0.001)$.

\section{Western blot and densitometry}

Western blots revealed the expression of claudin-1, claudin-2, claudin-3, claudin-4, claudin-5, claudin-7 and claudin- 8 and occludin in both controls and PP epithelium (Fig. 5a). Whereas stronger signals of claudin-2 and of claudin-7 were detected in controls compared to PP epithelium, PP revealed a stronger signal of the sealing TJ protein claudin-8. Surface correction
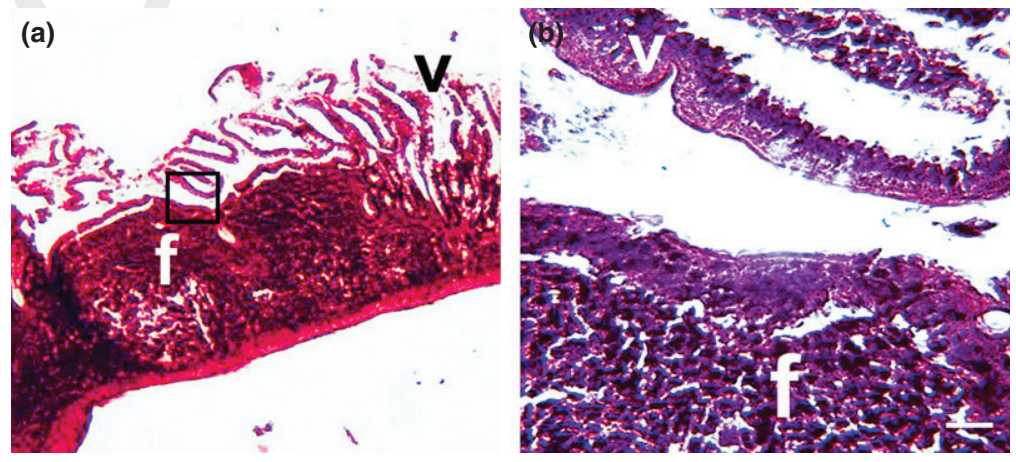

Figure I Haematoxylin and eosin staining of Peyer's patches and adjacent neighbouring villous epithelium. (a) Magnification $2.5 \times$, marked section indicates area of (b), magnification $40 \times$ (bar: $20 \mu \mathrm{m}$ ) and areas of follicles (f) of Peyer's patches and of adjacent neighbouring villous (v) epithelial tissues were clearly discriminated, allowing selection for Ussing chamber experiments, immunoblotting, immunohistochemistry and morphometry. 

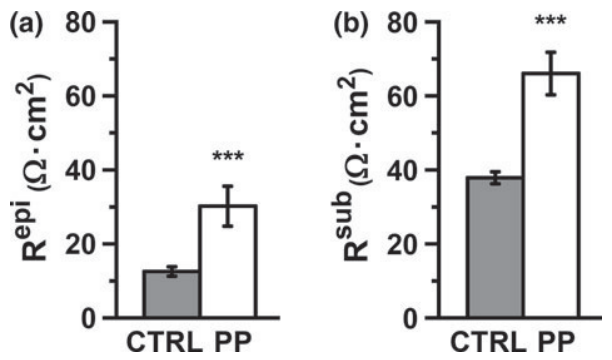

Figure 3 Impedance spectroscopy. Comparative analysis of epithelial resistance $\left(\mathrm{a} ; \mathrm{R}^{\mathrm{epi}}\right)$ and subepithelial resistance $(\mathrm{b}$; $\mathrm{R}^{\text {sub }}$ ) obtained by one-path impedance spectroscopy experiments revealed higher values of both $\mathrm{R}^{\mathrm{epi}}$ and $\mathrm{R}^{\mathrm{sub}}$ in Peyer's patches $(n=19$ and $25, * * * P<0.001)$.
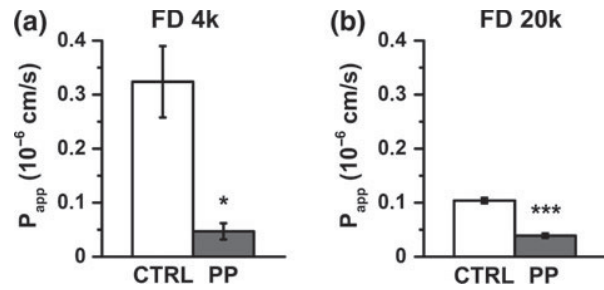

Figure 4 Effect on paracellular marker permeability. (a) 4 kDa FITC-dextran (FD 4k); (b) 20 kDa FITC-dextran (FD 20k). Permeability for both paracellular flux markers FD $4 \mathrm{k}$ and FD 20k was markedly and size-dependently lower in Peyer's patches epithelium compared to adjacent neighbouring villous epithelium $(n=3$, respectively; $* P<0.05$, *** $P<0.001)$.

of the data, however, resulted in stronger signals of tightening claudin-1, claudin-4, claudin-5 and claudin-8, whereas claudin-2 and claudin-7 were not significantly different from controls $(n=5-10$, $* P<0.05, \quad * * P<0.01, \quad * * * P<0.001$; $\quad$ Fig. 5b). These data are in accordance with stronger barrier properties of PP observed in electrophysiological experiments.

\section{Immunohistochemistry}

To investigate the distribution of TJ proteins within FAE, immunohistochemical analysis of PP tissue was performed. Tissue specimens were stained by antibodies raised against occludin and claudin-1, claudin-2, claudin-3, claudin-4, claudin-5, claudin-7 and claudin8 (Fig. 6). The majority of claudins was detected within apicolateral TJ areas of both PP and surface epithelium. Whereas occludin and claudin-1, claudin2, claudin-3, claudin-4, claudin-5 and claudin-7 showed predominant localization within TJ complexes, claudin-8 signals appeared rather faint in both controls and PP epithelial tissue specimens. Although not quantitatively assessed, signal intensity within tight junction complexes reflected differences in accordance with Western blot results, respectively.

\section{Discussion}

Primary functions of the intestinal mucosal villous epithelium are absorption, secretion and barrier function (Turner 2009). The main function of the FAE PP is considered to capture and present antigens to the underlying immunocompetent cells (Eri \& Chieppa 2013). Therefore, it seems probable that the epithelial 7 barrier is a prerequisite for the specific transcellular transport.

PP are located within the mucosa of the small intestine, which is generally defined as a leaky epithelium (Claude \& Goodenough 1973, Markov et al. 2010). The structural correlate of barrier function has been demonstrated to be provided by TJs, which are organized in strands, lining the apicolateral membrane of epithelial cells. Within the strands, members of the tetraspan TJ proteins have been reported, including occludin and the family of claudins (Furuse et al. 1993, 1998). Whereas a complete lack of occludin did (a)

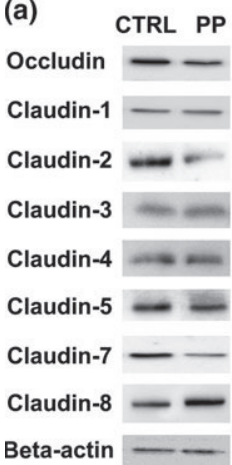

(b)

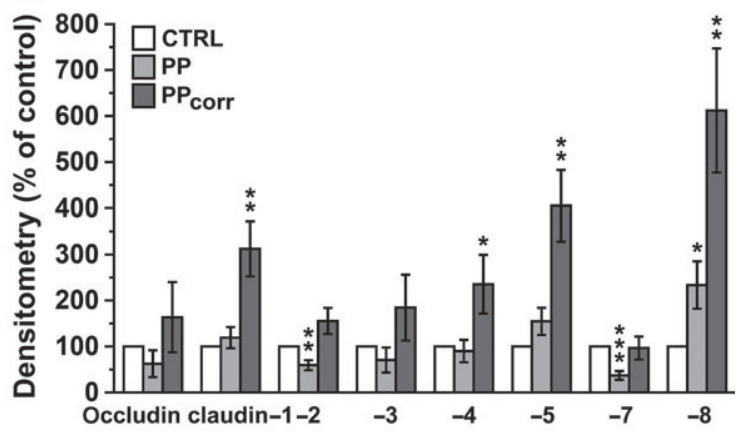

Figure 5 Western blots and densitometry. (a) Claudin-1, claudin-2, claudin-3, claudin-4, claudin-5, claudin-7, claudin-8, occludin and beta-actin were detected in Peyer's patches (PP) and villous epithelium. (b) Densitometric analysis of tight junction protein signals in villous epithelium (expressed as $100 \%$ ), Peyer's patches and respective signals after surface correction, representing material from $0.13 \mathrm{~cm}^{2}$ tissue area specimens, respectively $(n=5-10, * P<0.05, * * P<0.01, * * * P<0.001)$. 


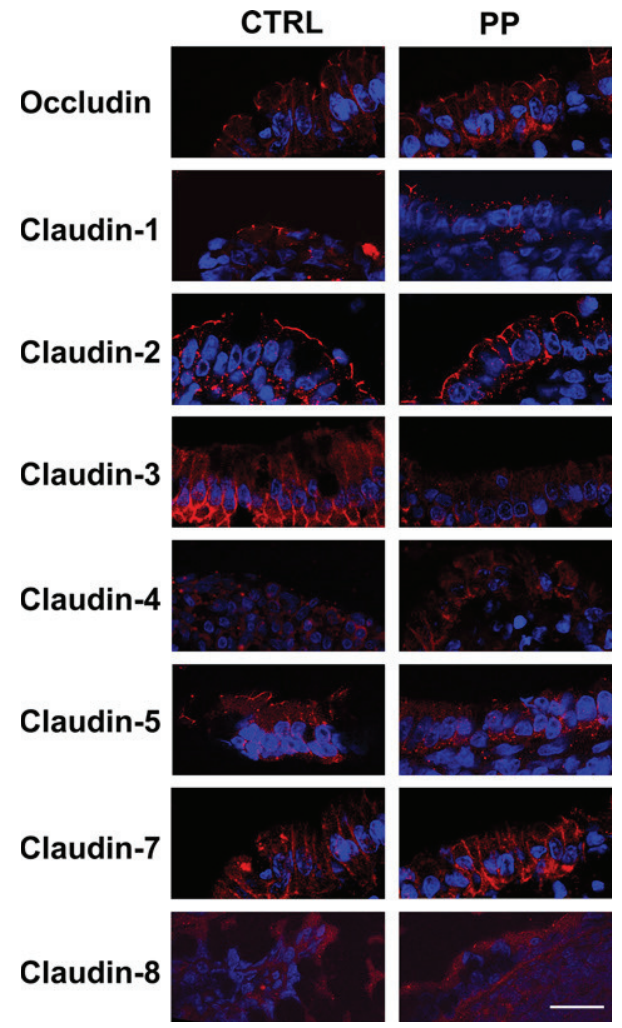

Figure 6 Confocal laser scanning immunofluorescence microscopy. Confocal imaging revealed signals of claudin-1, claudin-2, claudin-3, claudin-4, claudin-5, claudin-7 and claudin-8 and occludin in adjacent villous epithelia and PP. The majority of claudins was detected in the apicolateral membrane ( $n=5-10$, respectively, bar: $20 \mu \mathrm{m})$.

not result in changes of intestinal barrier properties, claudins emerged to be the main determinants of epithelial barrier function, homophilically and heterophilically interacting in cis and in trans, thereby determining tissue- and organ-specific epithelial barrier function (Furuse et al. 1999, Markov et al. 2015).

A first indication of different barrier function of PP and neighbouring small intestinal epithelium has been reported in rabbit intestine, showing different TER as a representative parameter of barrier function (Brayden \& Baird 1994). However, the measurement of TER does not discriminate between the contribution of the most apical epithelial cell layer providing the primary barrier by TJs and different thickness of subepithelial cell layers which may result in different contribution of a subepithelial resistance to total epithelial resistance. To overcome this limitation, onepath impedance spectroscopy has been established to discriminate between $\mathrm{R}^{\text {epi }}$ and $\mathrm{R}^{\text {sub }}$, with $\mathrm{R}^{\mathrm{epi}}$ representing the functionally relevant barrier parameter in intestine (Pappenheimer 1987, Gitter et al. 1997). This technique has also proven helpful when pathophysiological mechanisms affect the thickness of subepithelial tissue layers, for example in inflamed epithelia (Amasheh et al. 2004, 2009a).

One-path impedance spectroscopy allows a separated, but non-destructive measurement of epithelial and subepithelial ion conductance of the intestinal epithelium in vitro. As the conductivity of the epithelial cell layer is dependent on frequency, but not the subepithelial tissue layers due to a lack of tight junctions, this technique allows a structural assignment of intestinal permeability to the epithelium vs. subepithelium (Fromm et al. 1985, Gitter et al. 1998). In contrast, two-path impedance spectroscopy allows a discrimination between the paracellular and the transcellular pathway (Krug et al. 2009), which is only applicable in confluent monolayers without subepithelium, and therefore was not employed in our current study.

In our experiments, one-path impedance spectroscopy revealed that both $\mathrm{R}^{\text {sub }}$ and $\mathrm{R}^{\mathrm{epi}}$ were higher in PP compared to controls. As the apical monolayer of epithelial cells represents the physiologically relevant barrier, our results clearly demonstrate that the barrier function of FAE PP is stronger than that in the neighbouring located villous epithelium.

In PP, the paracellular pathway has been shown to be rather restrictive to the point that dendritic cells, mediating a passage of immunogens, also express TJ proteins including the tightening claudin-1 molecule (Rescigno et al. 2001). As dendritic cells open the TJs between epithelial cells and can take up microorganisms directly but at the same time preserve the integrity of the epithelial barrier, they may be regarded as an integrative factor of the apical cell monolayer itself, though. The higher subepithelial resistance of PP compared to adjacent neighbouring control tissue can be explained by different thickness alone as discussed also in context with chronic subepithelial immune cell infiltrations in inflammatory bowel disease (Amasheh et al. 2009a, b, Juric et al. 2013).

The understanding of the ultrastructure of TJs determining the permeability of the paracellular pathway has evolved in recent years, as especially the molecular TJ protein configuration and interaction within strands has been analysed in detail (Suzuki et al. 2014, 2015, Markov et al. 2015). Among the different membrane-spanning proteins located in intestinal TJ complexes, the family of claudins has been reported to primarily determine paracellular epithelial passage of ions and small molecules (Amasheh et al. 2002, 2005).

Our study revealed that in PP, claudin-1, claudin-2, claudin-3, claudin-4, claudin-5, claudin-7 and claudin8 are expressed. The same claudins were also detected in adjacent mucosal tissue specimens, but to a marked extent with different expression levels. These differ- 
ences are in accordance with the reported functional contribution of the single members of the claudin family. Generally, the detected claudins can be divided into three groups, namely proteins decreasing paracellular permeability (claudin-1, claudin-3, claudin-4, claudin-5 and claudin-8), claudin-2 mediating permeability and claudin-7 belonging to the group of claudins with ambiguous functions (Amasheh et al. 2011).

In PP, a stronger expression of claudin-1, claudin-4, claudin-5 and claudin- 8 was observed, compared to adjacent villous epithelia, which is in accordance with the higher values of $\mathrm{R}^{\mathrm{epi}}$. As the majority of claudins could also be detected within the apicolateral TJ complexes of both epithelial tissue specimens, the respective contribution of these claudins can be regarded as functionally evident. A minor drawback might be the lack of a specific detection of claudin- 8 within TJs, as this protein also shows strong quantitative differences in Western blots, but previous studies also showed only limited detection of the protein within small intestinal TJs (Markov et al. 2010). However, an also relatively weak detection of claudin- 8 in colon has been demonstrated to be overridden by selective recruitment in the apicolateral membrane in context with a synergistic regulatory process affecting both transport and barrier, as demonstrated for claudin-8 and $\mathrm{ENaC}$ in human colon (Amasheh et al. 2009b).

Finally, permeability measurements provide a striking proof-of-concept of our study, as the permeability of paracellular flux markers 4 and $20 \mathrm{kDa}$ FITC-dextran was markedly and size-dependently lower in Peyer's patches compared to adjacent neighbouring villous epithelium. As known immunogens typically have comparable sizes, for example lipopolysaccharides or other bacterial compounds, this provides a striking hint on a maximum paracellular sealing function by PP tight junctions, providing a selective transcellular pathway for a controlled immunoreaction.

Taken together, molecular composition and functional parameters of the $\mathrm{TJ}$ clearly indicate a major restriction of the paracellular pathway in PP, underlining the role of a regulated and controlled transcellular passage of immunogens to underlying immune cells. This finding highlights a physiologically strong limitation of the paracellular transport of substances in the FAE of PP as a prerequisite for specific presentation of antigenic structures of immunocompetent cells through specialized $\mathrm{M}$ cells. As the TJ has also been reported to be sensitive to the action of a variety of substances and mediators, selective disturbances of PP claudin composition, for example in inflammatory processes or by food components, may also specifically affect the local processes of antigenic presentation.

\section{Conflict of interest}

The authors declared no conflict of interest.

This study is supported by grants of the Deutsche Forschungsgemeinschaft, Grant No. AM 141/4-3, the Center for International Cooperation (CIC), the Partnership programme of Freie Universität Berlin-St. Petersburg State University, a Grant of the St. Petersburg State University (1.38.231.2014) and Grant RFBR 13-04-01107. The research was supported by the Research Resource Center 'Molecular and Cell Technologies' of St. Petersburg State University. We thank Michael Fromm and the staff at the Institute of Clinical Physiology, Charité - Universitätsmedizin Berlin for support. This work is dedicated to Detlef Sorgenfrei.

\section{References}

Amasheh, S., Meiri, N., Gitter, A.H., Schöneberg, T., Mankertz, J., Schulzke, J.D. \& Fromm, M. 2002. Claudin-2 expression induces cation-selective channels in tight junctions of epithelial cells. J Cell Sci 115, 4969-4976.

Amasheh, S., Barmeyer, C., Koch, C.S., Tavalali, S., Mankertz, J., Epple, H.J., Gehring, M.M., Florian, P., Kroesen, A.J., Zeitz, M., Fromm, M. \& Schulzke, J.D. 2004. Cytokine-dependent transcriptional down-regulation of epithelial sodium channel in ulcerative colitis. Gastroenterology 126, 1711-1720.

Amasheh, S., Schmidt, T., Mahn, M., Florian, P., Mankertz, J., Tavalali, S., Gitter, A.H., Schulzke, J.D. \& Fromm, M. 2005. Expression of claudin-5 contributes to barrier properties in tight junctions of epithelial cells. Cell Tissue Res 321, 89-96.

Amasheh, S., Dullat, S., Fromm, M., Schulzke, J.D., Buhr, H.J. \& Kroesen, A.J. 2009a. Inflamed pouch mucosa possesses altered tight junctions indicating recurrence of inflammatory bowel disease. Int I Colorectal Dis 24, 1149-1156.

Amasheh, S., Milatz, S., Krug, S.M., Bergs, M., Amasheh, M., Schulzke, J.D. \& Fromm, M. 2009b. Na ${ }^{ \pm}$absorption defends from paracellular back-leakage by claudin- 8 upregulation. Biochem Biophys Res Commun 378, 45-50.

Amasheh, S., Fromm, M. \& Günzel, D. 2011. Claudins of intestine and nephron - a correlation of molecular tight junction structure and barrier function. Acta Physiol (Oxf) 201, 133-140.

Brayden, D.J. \& Baird, A.W. 1994. A distinctive electrophysiological signature from the Peyer's patches of rabbit intestine. Br J Pharmacol 113, 593-599.

Clark, M.A. \& Hirst, B.H. 2002. Expression of junction-associated proteins differentiates mouse intestinal $\mathrm{M}$ cells from enterocytes. Histochem Cell Biol 118, 137-147.

Claude, P. \& Goodenough, D.A. 1973. Fracture faces of zonulae occludentes from "tight" and "leaky" epithelia. J Cell Biol 58, 390-400.

Eri, R. \& Chieppa, M. 2013. Messages from the inside. The dynamic environment that favors intestinal homeostasis. Front Immunol 4, 323. 
Fromm, M., Schulzke, J.D. \& Hegel, U. 1985. Epithelial and subepithelial contributions to transmural electrical resistance of intact rat jejunum, in vitro. Pflugers Arch 405, 400-402.

Furuse, M., Hirase, T., Itoh, M., Nagafuchi, A., Yonemura, S., Tsukita, S. \& Tsukita, S. 1993. Occludin: a novel integral membrane protein localizing at tight junctions. J Cell Biol 123, 1777-1788.

Furuse, M., Fujita, K., Hiiragi, T., Fujimoto, K. \& Tsukita, S. 1998. Claudin-1 and -2: novel integral membrane proteins localizing at tight junctions with no sequence similarity to occludin. J Cell Biol 141, 1539-1550.

Furuse, M., Sasaki, H. \& Tsukita, S. 1999. Manner of interaction of heterogeneous claudin species within and between tight junction strands. J Cell Biol 147, 891-903.

Gebert, A., Rothkötter, H.J. \& Pabst, R. 1996. M cells in Peyer's patches of the intestine. Int Rev Cytol 167, 91159.

Gitter, A.H., Schulzke, J.D., Sorgenfrei, D. \& Fromm, M. 1997. Ussing chamber for high-frequency transmural impedance analysis of epithelial tissues. I Biochem Biophys Methods 35, 81-88.

Gitter, A.H., Fromm, M. \& Schulzke, J.D. 1998. Impedance analysis for the determination of epithelial and subepithelial resistance in intestinal tissues. I Biochem Biophys Methods 37, 35-46.

Hackel, D., Krug, S.M., Sauer, R.S., Mousa, S.A., Böcker, A., Pflücke, D., Wrede, E.J., Kistner, K., Hoffmann, T., Niedermirtl, B. et al. 2012. Transient opening of the perineurial barrier for analgesic drug delivery. Proc Natl Acad Sci USA 109, E2018-E2027.

Jung, C., Hugot, J.P. \& Barreau, F. 2010. Peyer's Patches: the Immune Sensors of the Intestine. Int I Inflam 2010, 823710.

Juric, M., Xiao, F., Amasheh, S., May, O., Wahl, K., Bantel, H., Manns, M.P., Seidler, U. \& Bachmann, O. 2013. Increased epithelial permeability is the primary cause for bicarbonate loss in inflamed murine colon. Inflamm Bowel Dis 19, 904-911.

Keita, A.V. \& Söderholm, J.D. 2012. Barrier dysfunction and bacterial uptake in the follicle-associated epithelium of ileal Crohn's disease. Ann N Y Acad Sci 1258, 125-134.

Koval, M. 2013. Claudin heterogeneity and control of lung tight junctions. Annu Rev Physiol 75, 551-567.

Krug, S.M., Fromm, M. \& Günzel, D. 2009. Two-path impedance spectroscopy for measuring paracellular and transcellular epithelial resistance. Biophys J 97, 22022211.

Markov, A.G., Veshnyakova, A., Fromm, M., Amasheh, M. \& Amasheh, S. 2010. Segmental expression of claudin proteins correlates with tight junction barrier properties in rat intestine. Comp J Physiol Biochem B 80, 591-598.

Markov, A.G., Kruglova, N.M., Fomina, Y.A., Fromm, M. \& Amasheh, S. 2012. Altered expression of tight junction proteins in mammary epithelium after discontinued suckling in mice. Pflügers Arch 463, 391-398.
Markov, A.G., Falchuk, E.L., Kruglova, N.M., Rybalchenko, O.V., Fromm, M. \& Amasheh, S. 2014. Comparative analysis of theophylline and cholera toxin in rat colon reveals an induction of sealing tight junction proteins. Pflugers Arch 466, 2059-2065.

Markov, A.G., Aschenbach, J.R. \& Amasheh, S. 2015. Claudin clusters as determinants of epithelial barrier function. IUBMB Life 67, 29-35.

Pappenheimer, J.R. 1987. Physiological regulation of transepithelial impedance in the intestinal mucosa of rats and hamsters. J Membr Biol 100, 137-148.

Persson, P.B. 2013. Good publication practice in physiology 2013 guidelines for acta physiologica. Acta Physiol (Oxf) 209, 250-253.

Rescigno, M., Urbano, M., Valzasina, B., Francolini, M., Rotta, G., Bonasio, R., Granucci, F., Kraehenbuhl, J.P. \& Ricciardi-Castagnoli, P. 2001. Dendritic cells express tight junction proteins and penetrate gut epithelial monolayers to sample bacteria. Nat Immunol 2, 361-367.

Rittner, H.L., Amasheh, S., Moshourab, R., Hackel, D., Yamdeu, R.S., Mousa, S.A., Fromm, M., Stein, C. \& Brack, A. 2012. Modulation of tight junction proteins in the perineurium to facilitate peripheral opioid analgesia. Anesthesiology 116, 1323-1334.

Rosenthal, R., Milatz, S., Krug, S.M., Oelrich, B., Schulzke, J.D., Amasheh, S., Günzel, D. \& Fromm, M. 2010. Claudin-2, a component of the tight junction, forms a paracellular water channel. J Cell Sci 123, 1913-1921.

Smith, M.W., Jarvis, L.G. \& King, I.S. 1980. Cell proliferation in follicle-associated epithelium of mouse Peyer's patch. Am J Anat 159, 157-166.

Suzuki, H., Nishizawa, T., Tani, K., Yamazaki, Y., Tamura, A., Ishitani, R., Dohmae, N., Tsukita, S., Nureki, O. \& Fujiyoshi, Y. 2014. Crystal structure of a claudin provides insight into the architecture of tight junctions. Science 18, 304-307.

Suzuki, H., Tani, K., Tamura, A., Tsukita, S. \& Fujiyoshi, Y. 2015. Model for the architecture of claudin-based paracellular ion channels through tight junctions. J Mol Biol 30, 291-297.

Tamagawa, H., Takahashi, I., Furuse, M., Yoshitake-Kitano, Y., Tsukita, S., Ito, T., Matsuda, H. \& Kiyono, H. 2003. Characteristics of claudin expression in follicle-associated epithelium of Peyer's patches: preferential localization of claudine-4 at the apex of the dome region. Lab Invest 83, 1045-1053.

Troeger, H., Epple, H.J., Schneider, T., Wahnschaffe, U., Ullrich, R., Burchard, G.D., Jelinek, T., Zeitz, M., Fromm, M. \& Schulzke, J.D. 2007. Effect of chronic Giardia lamblia infection on epithelial transport and barrier function in human duodenum. Gut 56, 328-335.

Turner, J.R. 2009. Intestinal mucosal barrier function in health and disease. Nat Rev Immunol 9, 799-809.

Van Itallie, C.M. \& Anderson, J.M. 2014. Architecture of tight junctions and principles of molecular composition. Semin Cell Dev Biol 36, 157-165. 


\section{Author Query Form}

\section{Journal: APHA \\ Article: 12559}

Dear Author,

During the copy-editing of your paper, the following queries arose. Please respond to these by marking up your proofs with the necessary changes/additions. Please write your answers on the query sheet if there is insufficient space on the page proofs. Please write clearly and follow the conventions shown on the attached corrections sheet. If returning the proof by fax do not write too close to the paper's edge. Please remember that illegible mark-ups may delay publication.

Many thanks for your assistance.

\begin{tabular}{|l|l|l|}
\hline Query reference & Query & $\begin{array}{l}\text { Remar- } \\
\text { ks }\end{array}$ \\
\hline 1 & $\begin{array}{l}\text { AUTHOR: Please confirm that given names (red) and surnames/family } \\
\text { names (green) have been identified correctly. }\end{array}$ \\
\hline 2 & $\begin{array}{l}\text { AUTHOR: Markov et al. } 2013 \text { has been changed to Markov et al. } 2012 \text { so } \\
\text { that this citation matches the Reference List. Please confirm that this is } \\
\text { correct. }\end{array}$ \\
\hline 3 & $\begin{array}{l}\text { AUTHOR: Keita } \text { et al. } 2012 \text { has been changed to Keita and Söderholm 2012 } \\
\text { so that this citation matches the Reference List. Please confirm that this is } \\
\text { correct. }\end{array}$ \\
\hline 4 & AUTHOR: Please provide city for "Sigma Aldrich". \\
\hline 5 & $\begin{array}{l}\text { AUTHOR: Dittmann et al. } 2014 \text { has not been included in the Reference } \\
\text { List, please supply full publication details. }\end{array}$ \\
\hline 6 & AUTHOR: Please provide city and state for “Life Technologies". \\
\hline 8 & $\begin{array}{l}\text { AUTHOR: Eri } 2013 \text { has been changed to Eri and Chieppa 2013 so that this } \\
\text { citation matches the Reference List. Please confirm that this is correct. }\end{array}$ \\
\hline $\begin{array}{l}\text { AUTHOR: Amasheh et al. } 2009 \text { has been changed to Amasheh et al. 2009a, } \\
\text { 2009b so that this citation matches the Reference List. Please confirm that } \\
\text { this is correct. }\end{array}$ \\
\hline
\end{tabular}

